\title{
A missão educacional ao Uruguai: o que dizem os jornais A Federação e o Correio do Povo
}

The educational mission to Uruguay: what the newspapers $A$ Federação and Correio do Povo say

\author{
Caroline Braga Michel* \\ Universidade Federal de Pelotas \\ Eduardo Arriada ** \\ Universidade Federal de Pelotas
}

Resumo $\mathrm{O}$ objetivo deste artigo é analisar como a missão educacional encaminhada ao Uruguai pelo governador do Estado do Rio Grande do Sul, Antonio Augusto Borges de Medeiros, foi abordada na imprensa sul-rio-grandense. Para tanto, trabalhamos com as edições dos anos de 1913 e 1914 de dois periódicos: A Federação e o Correio do Povo. A análise das reportagens evidenciou um interesse das autoridades governamentais em noticiar por meio dos periódicos locais, o andamento da missão educacional enviada ao país vizinho. Para além do interesse da possibilidade real de alavancar a educação sul-rio-grandense, o governo republicano buscava também vender a imagem de uma administração moderna, eficiente e preocupada com os rumos a serem tomados pelo Estado.

PALAVRAS-ChAVE: A Federação; Correio do Povo; Missão Educacional.

\begin{abstract}
This paper aims to discuss how the educational mission sent to Uruguay by the governor of the State of Rio Grande do Sul, Antonio Augusto Borges de Medeiros, was addressed by the local press. To this end, the issues of the years 1913 and 1914 of two newspapers were taken for analysis: A Federação and Correio do Povo. Results showed an interest of government authorities in reporting through such newspapers the ongoing educational mission sent to the neighboring country. Apart from the interest of the real possibility of leveraging education in the State, the Republican government also sought to sell the image of a modern and efficient administration, concerned with the direction to be taken by the State.
\end{abstract}

KEYWORDS: A Federação (The Federation); Correio do Povo (People's Post); Educational Mission. 


\section{Introdução}

No final do século XIX, assim como nas primeiras décadas do século XX, havia a prática por parte das autoridades brasileiras de enviar missões educacionais para fora do país com a finalidade primordial de identificar os métodos de ensino utilizados pelas nações desenvolvidas. Contudo, cabe salientar que nesse período essa prática já estava consolidada como uma estratégia importante para os países obterem mudanças e maior qualidade em seus setores educacionais.

Neste sentido, ressaltamos que missões e viagens vinham sendo realizadas desde o Império. De caráter particular, salientamos as efetivadas por Abílio César Borges (1824-1891) - médico, professor, diretor de escola e membro do Conselho de Instrução Pública da Corte. O Barão de Macaúbas, como era conhecido, realizou três viagens pedagógicas à Europa, 1866, 1870 e 1879, buscando práticas e modelos escolares que pudessem contribuir com a qualidade de sua instituição.

Patrocinadas pelo erário público, ressaltamos duas missões: a realizada pelo Inspetor-geral de Instrução Pública Antônio Herculano de Souza Bandeira Filho e a de Antônio Almeida de Oliveira. O primeiro dedicou-se a observar, na Europa, as instituições de Educação Infantil. A partir de suas visitas à França, Suíça, Áustria e Alemanha publicou, em 1883, um circunstanciado relatório de viagem. E o segundo, educador e político de tendência liberal, viajou para os Estados Unidos no início dos anos de 1870, onde conheceu diversas escolas de Boston, Massachusetts e Brooklin (CHAMON; FILHO, 2007).

Como evidenciado através desses exemplos, as missões e viagens foram sendo realizadas em diferentes períodos bem como se cristalizando como práticas de investimento em prol de mudanças e avanços educacionais, pois, a medida que os sujeitos retornavam para seus países eles poderiam, através de suas observações, analisar, comparar e propor outras possibilidades de organização. Por essa razão, quanto mais informações e detalhes os viajantes ou comissionados apresentassem, mais ampliado seria o conhecimento que seu povo teria sobre as outras nações. Logo, os registros escritos sobre essas viagens, fossem eles livros, relatórios oficiais, cartas, entre outros, era uma forma de divulgar suas impressões e os saberes adquiridos com os modelos internacionais.

Sobre esses registros é importante destacar que alguns foram publicados apenas após um longo período de elaboração enquanto outros foram redigidos em um curto espaço de tempo sendo, por vezes, divulgados em revistas. De modo similar, e muitas vezes complementar, os periódicos jornalísticos para além de noticiarem informações como, por exemplo, a data de partida e o regresso dos viajantes, também transcreviam alguns trechos desses registros, ora em uma única reportagem ora em sucessivas edições.

Considerando, portanto, que tanto informações a respeito das viagens, como também observações e impressões dos viajantes foram publicadas em diferentes impressos foi que voltamos nossa atenção especificamente para os periódicos jornalísticos. Assim, compreendendo que na época em que o governo gaúcho encaminhou uma 
missão educacional ao Uruguai, primeira década do século XX, os jornais rio-grandenses noticiavam e informavam sobre diversos acontecimentos bem como eram, em sua maioria, vinculados a partidos políticos (SILVA, 1986; ALVES, 2006; FRANCO, 2010) foi que objetivamos identificar o que foi divulgado nos periódicos jornalísticos sobre a iniciativa do governo de Antônio Augusto Borges de Medeiros de enviar ao Uruguai, em 1913 e em 1914, uma missão educacional.

Compreendendo a potencialidade dos impressos jornalísticos como "arquivos do cotidiano" (ZICMAM, 1985), o uso do jornal como fonte, especialmente, as edições de $A$ Federação e o Correio do Povo se mostraram como uma possibilidade de analisar como essa prática foi noticiada pelos dois jornais com papéis e posicionamentos diferenciados bem como se configura em uma contribuição importante para a história da educação do Rio Grande do Sul tendo em vista que até o momento nenhuma pesquisa foi realizada sobre o assunto.

Sendo assim, a escolha por contemplar nesta análise o jornal $A$ Federação deve-se ao fato desse impresso ter se constituído como órgão do Partido Republicano Rio-Grandense (PRR) e a opção pelo Correio do Povo deve-se ao fato dele configurar-se como um periódico independente - não estando vinculado diretamente a um partido político e/ou ao governo.

Para a contextualização do Rio Grande do Sul utilizamos principalmente os trabalhos de Tambara (1995), Giolo (1997) e Corsetti (1998) e, para o cenário uruguaio, os de Bralich (1987), Barran (1998), Caetano (2000) e Greissing (2000). As discussões acerca do papel da imprensa e do trabalho metodológico com os jornais pautou-se nas contribuições de Alves (2006) e Luca (2005).

Diante do exposto, organizamos este artigo em quatro seções. Na primeira, contextualizamos os cenários do Rio Grande do Sul e do Uruguai, na segunda discorremos sobre a organização da missão pelo governo gaúcho. Na terceira, analisamos as reportagens divulgadas pelos dois jornais. E, por fim, na quarta seção expomos algumas conclusões.

\section{O contexto do RGS e o contexto uruguaio}

Nas administrações republicanas durante o período da República Velha (1890-1930), o Governo do Estado contou sempre com a participação efetiva do Partido Republicano Rio-Grandense (PRR), ocupando o presidente do Estado, a chefia do partido. Sendo que no período pesquisado nesse trabalho esteve como presidente do Estado, Antônio Augusto Borges de Medeiros.

As principais características do PRR eram: a defesa do federalismo, a ideologia positivista, inspirada em Augusto Comte, e a condenação do sistema escravocrata. Pautadas nessas premissas, as ações desenvolvidas por este partido acarretaram mudanças significativas no Estado do RGS no que tange a economia, a política e a cultura uma vez que o Projeto Republicano tinha como objetivo eliminar todo e qualquer resquício do passado que fosse referente a estagnação, a escravidão e a ignorância (TAMBARA, 1995; GIOLO, 1997; CORSETTI, 1998). 
Neste contexto, a educação por sua vez, recebeu atenção especial e foi compreendida como um instrumento fundamental de propaganda do ideário positivista do governo gaúcho passando a ser vinculada à formação social. Pois, era através da educação que os sujeitos poderiam sair da "ignorância" e serem educados de forma a ter aptidão para governar-se e adquirir o gosto pelo exercício da liberdade e a consciência nacional.

Embora nos anos iniciais da República Velha os dirigentes identificassem alguns avanços no setor educacional o Estado tinha conhecimento que havia em relação ao desenvolvimento da rede de ensino pública falhas. Tambara (1995) salienta que, dentre outros, um dos aspectos que foi compreendido como fator de "estrangulamento do desenvolvimento da rede de ensino pública foi o processo de formação de professores" (TAMBARA, 1995, p. 284). Além da Escola Complementar ${ }^{1}$ receber um número ínfimo de matrículas e, consequentemente, o Estado ter um número reduzido de profissionais para atender as escolas que vinham sendo criadas, o autor destaca que a frágil formação destinada a essas pessoas também contribuía para o não progresso e a pouca qualificação do ensino público.

Assim, a fim de superar essas e outras contingências relativas à instrução pública, diferentes medidas foram sendo adotadas pelo governo gaúcho. Dentre elas, a decisão em 1913, de organizar uma missão pedagógica para ser encaminhada ao Uruguai. A mesma tinha como intuito estudar a organização, os métodos, e outros aspectos relativos ao sistema de ensino uruguaio no intuito de identificar 'possibilidades modernas' que contribuíssem para a superação das contingências enfrentadas pelo Estado no setor educacional. A escolha do país vizinho como destino para o estudo teve como principal justificativa, pelo governo gaúcho, o fato de o Uruguai apresentar uma notável distinção entre os países latino-americanos, sendo considerada uma República adiantada que vinha, nas primeiras décadas do século XX, obtendo cada vez mais destaque.

Sob o governo de Batlle y Ordóñez - expresso através de uma atitude paternalista, da atuação enquanto mediador nos intensos conflitos sociais que se produziram nesse início do século (enfrentamentos de trabalhadores e classe patronal), e também na atuação como impulsionador de um desenvolvimento industrial voltado à substituição das importações -, o contexto uruguaio mostrou significativos avanços (BRALICH, 1987).

No plano social, por exemplo, houve um crescimento vegetativo da população, assim como uma acelerada taxa de urbanização da mesma. No último quarto do século XIX a população duplicou, passando de 500.000 mil habitantes para 1.000.000, e no primeiro quarto do século XX, atingiu a cifra de 1.500.000. Já no plano cultural e educacional, pode-se destacar a expansão do sistema público de educação que chegou a atender quase a totalidade da população. Nesse sentido, cabe salientar no que faz referência ao ensino primário, o crescimento da população escolar que passou de 45.617 matriculados em 1897, para 74.717 em 1910, atingindo 157.300 no ano de 1930 . O número de escolas para atender essa população escolar cresceu também de $545 \mathrm{em}$ 1897 para 1.100 escolas no ano de 1930 (BRALICH, 1987, p. 80). 
Sobre os discursos que foram organizando e constituindo um projeto educacional nesta época para a sociedade uruguaia, é importante destacar as contribuições e o legado de José Pedro Varela. Seu projeto foi aprovado pelo governo em 1877, com algumas alterações, e defendia a escola pública gratuita, obrigatória e laica já que a educação era considerada como um serviço de utilidade pública e como condição para a participação cívica e um bem irrefutável ao progresso.

Contextualizados, ainda que brevemente o cenário rio-grandense e o uruguaio, passamos a discorrer a decisão e organização da missão encaminhada ao Uruguai.

\section{A missão encaminhada ao Uruguai}

A missão organizada pelo presidente do Estado do Rio Grande do Sul e encaminhada a Montevidéu com o objetivo de "conhecer de perto os sistemas e processos educativos postos em prática nas aulas públicas desta pequena, mas adiantada $\mathrm{e}$ florescente República" (RELATÓRIO, 1914) foi desenvolvida em dois momentos: o primeiro no ano de 1913 e, o segundo, no ano de 1914.

Em 1913, o grupo encaminhado a Montevidéu foi liderado pelo Diretor da Escola Complementar Alfredo Clemente Pinto, e composto por Afonso Guerreiro Lima, Ondina Godoy Gomes, Georgina Godoy Moritz, Marieta de Freitas Chaves e Florinda Tubino, sendo os três primeiros professores da Escola Complementar e as duas últimas auxiliares de ensino da mesma escola. E tinha como objetivo específico "estudar os methodos de ensino ali adoptados nas aulas publicas e tudo quanto diga respeito a esse importantíssimo ramo de serviço” (A FEDERAÇÃO, 01/09/1913, p. 5).

O embarque deste grupo, em 15/09/1913, foi noticiado tanto pela $A \mathrm{Fe}^{-}$ deração como pelo $O$ Correio do Povo e, segundo as informações de ambos os jornais, estiveram presentes para a despedida, autoridades como Protásio Antônio Alves - Secretário dos Negócios do Interior e Exterior -, e diversos professores e alunos da capital rio-grandense, mostrando assim, ter sido este um momento importante para o setor educacional na época.

Permanecendo três meses no país vizinho, os comissionados observaram duas escolas de $1^{\circ}$ grau e de $2^{\circ}$ grau, uma escola de $3^{\circ}$ grau, uma escola de Aplicação, o Jardim de Infância, o Asilo Maternal, a Escola ao Ar Livre, o Instituto de Surdos-Mudos e o Museu e Biblioteca Pedagógica. As impressões dessa primeira viagem foram registradas em um Relatório que foi entregue ao Diretor Geral Firmino Paim Filho e à Protásio Antônio Alves. Nesse documento foram descritas inúmeras facetas do funcionamento do sistema educacional uruguaio, as quais serão apresentadas posteriormente a partir das notícias publicadas pelos jornais.

Em 1914, ocorreu o segundo momento da missão. A partir de um acordo estabelecido entre os governos do Uruguai e do Rio Grande do Sul, ainda no ano de 1913, três alunas mestras e três professoras adjuntas foram, respectivamente, aperfeiçoar seus estudos no Instituto Nacional de Senhoritas - responsável pela formação de professores -, e praticar os métodos de ensino utilizados nessa escola e na de Aplicação 
da Capital uruguaia - escola anexa onde os futuros professores praticavam as lições de ensino.

Assim, permaneceram em Montevidéu durante o ano de 1914, Carolina Cunha, Olga Acauan, Marina Cunha, Idalina Mariante Pinto, Maria José de Souza e Branca Diva Pereira. As três primeiras receberam apoio financeiro tanto do governo gaúcho como um subsídio mensal de 90 pesos do governo uruguaio (A FEDERAÇÃO,09/04/1914,p. 4) e as outras três receberam apenas auxílio financeiro do governo rio-grandense. Pelas pesquisas realizadas até o presente momento não identificamos um Relatório que tenha sido encaminhado por este grupo aos dirigentes do Estado.

Exposto a organização da missão passamos a tratar da divulgação da mesma através da imprensa sul-rio-grandense.

\section{O que dizem os jornais A Federação e o Correio do Povo?}

Como mencionado na Introdução deste artigo, para analisarmos como a missão pedagógica encaminhada ao Uruguai foi abordada na imprensa sul -rio-grandense pesquisamos as edições de 1913 e 1914 de dois jornais: A Federação e o Correio do Povo.

A Federação foi criado em Porto Alegre em 1884 como um veículo de propagação das ideias defendidas pelo Partido Republicano Rio-grandense (PRR) e começou a circular no dia $1^{\circ}$ de Janeiro do referido ano, como órgão do PRR. Segundo Espig (2013) A Federação é um dos expoentes máximos do jornalismo político-partidário. No período da pesquisa realizada neste trabalho, a redação e administração do jornal estavam localizadas na Rua das Andradas, no 94 e tinha como Diretor de Redação Ildefonso Pinto e como Gerente, H. de Barros Figueiredo Junior. A circulação do periódico ocorria de segunda a sábado e, geralmente, continha de 6 a 8 páginas, custando cada número avulso 100 réis. Em algumas situações como, por exemplo, datas comemorativas, campanhas eleitorais ou transcrição de leis e decretos, foi possível identificar edições com 12 a 20 páginas.

Quanto ao Correio do Povo, ele foi criado em 1895, em Porto Alegre, por Francisco Antonio Vieira Caldas Júnior e, segundo constava em suas próprias edições, se caracterizava por ser um jornal informativo. Como gerente da empresa nos anos investigados estava João Obino. Sua periodicidade também tinha como exceção o domingo e o número médio de páginas era 6, custando o jornal avulso na capital 100 réis e fora da capital, 200 réis.

A partir das análises das edições dos anos de 1913 e de 1914 de ambos os jornais identificamos um total de 43 reportagens que abordavam algum aspecto sobre a missão, fossem eles no sentido de anunciar, informar, ou ainda, de argumentar sobre a deliberação do governo gaúcho. No quadro a seguir, apresentamos a distribuição das mesmas por periódicos. 
Quadro 1 - Número de reportagens sobre a missão pedagógica

\begin{tabular}{|l|l|l|l|}
\hline Periódicos & Ano de 1913 & Ano de 1914 & Total de reportagens \\
\hline A Federação & 28 & 5 & 33 \\
\hline Correio do Povo & 6 & 4 & 10 \\
\hline
\end{tabular}

Fonte: Quadro organizado pelos autores a partir dos jornais A Federação e o Correio do Povo de 1913 e 1914

A distribuição das reportagens apresentada no quadro acima nos possibilita, de antemão, identificar que o jornal $A$ Federação publicou um número maior de reportagens sobre a missão do que o Correio do Povo. Nesse sentido, lembramos as palavras de Luca (2005) ao destacar a importância de ao trabalharmos com jornais considerarmos suas ligações políticas, econômicas bem como as formas com que cada objeto é tratado e o grupo responsável por sua publicação. Desse modo, enfatizamos, como já destacado, o papel que o periódico tinha enquanto órgão do PRR e, logo, a ação do seu próprio governo não poderia passar despercebida.

É possível observar ainda a partir dos dados do quadro que, quantitativamente, a missão teve uma divulgação mais ampla no ano de 1913, inclusive, houve uma diferença significativa entre o número de reportagens noticiadas entre a $A$ Federação e o Correio do Povo. Fato esse que não ocorreu no ano de 1914 uma vez que a diferença entre o número de reportagens publicadas é ínfimo. Contudo, sobre esse aspecto, é importante ressaltar que fazendo a leitura das notícias referentes ao ano de 1914 identificamos que do total das cinco reportagens publicadas em $A$ Federaşão apenas duas eram referentes a viagem das alunas que estavam em Montevidéu, sendo as outras três publicações com trechos da Relatório organizado pelo grupo que esteve em Montevidéu em 1913. Essa observação incide na constatação de que, embora quantitativamente, a diferença entre os dois jornais seja reduzida, no ano de 1914 o Correio do Povo foi o periódico que mais noticiou o segundo momento da missão.

Categorizar as 43 reportagens nos permitiu aprofundar as análises e identificar como a missão foi abordada nos dois impressos. Assim, considerando os conteúdos das notícias apresentadas nos jornais subdividimos o total das reportagens em três categorias. São elas: (i) reportagens de caráter informativo: as quais versavam, por exemplo, sobre a decisão do governo em organizar a missão; o dia de embarque dos grupos; o atraso no regresso do grupo de 1913, devido a doença do Sr. Clemente Pinto, etc; (ii) reportagens com as impressões da viagem: apresentavam as impressões dos comissionados, fossem elas críticas, elogios, comparações, ou ainda, as atividades que estavam sendo realizadas no Uruguai. E, por fim, as (iii) reportagens argumentativas: as caracterizamos dessa forma pelo fato de contemplarem argumentos que respaldavam a necessidade da missão e justificavam a escolha do Uruguai como destino.

A partir dessa categorização, evidenciamos que do total das 33 reportagens publicadas em $A$ Federação, 12 eram de caráter informativo, 5 trataram sobre as impressões obtidas na viagem e 16 das reportagem foram publicadas com o intuito de justificar e/ou respaldar a estratégia adotada pelo governo. No que diz respeito as 10 reportagens publicadas pelo Correio do Povo, foi possível identificar que 5 abordaram 
informações sobre a missão, 2 discorreram sobre as impressões dos grupos e 3 eram de carácter argumentativo.

Foi entre as reportagens informativas que encontramos a primeira notícia sobre a missão. Ela foi divulgada pelo jornal $A$ Federação na edição de 01 de Setembro de 1913. Foi uma pequena reportagem, na seção Varias, anunciado que o governo havia nomeado uma comissão de professores da Escola Complementar para estudar na Capital do Uruguai os aspectos relativos ao serviço da instrução pública lá ministrados. Cabe destacar que a reportagem foi editada tendo uma dimensão pequena e o título não tinha ligação direta com a decisão do governo, o qual era: Ensino Público. Sobre a seção do jornal em que essa reportagem foi publicada, salientamos que ela estava localizada nas últimas páginas do jornal e que tinha por característica apresentar informações dos mais variados ramos. Inferimos a partir dessas questões que não houve, inicialmente, uma preocupação demasiada por parte do governo em divulgar a estratégia que o mesmo estava adotando para qualificar o ensino público.

Contudo, observamos nas edições seguintes a essa "modesta" notícia, que $A$ Federação publicou uma sucessão de reportagens buscando caracterizar o ensino público no Rio Grande do Sul, bem como, respaldar a opção do governo em encaminhar o grupo de professores ao Uruguai. Evidenciamos que tal episódio ocorreu devido a uma contestação apresentada, na seção Pequenas Notas, do jornal Correio do Povo em que o articulista do Correio do Povo, o jornalista Francisco Leonardo Truda (Léo D’Utra), se mostrou contrário a tal decisão, advertindo em seu artigo que encaminhar uma comissão de professores ao Uruguai não era uma ação eficaz. E foi em virtude desse posicionamento do jornalista do Correio do Povo, que foram publicadas em sequência, em $A$ Federação, 13 reportagens argumentativas. Isto é, que apresentavam argumentos respaldando a ação do governo e a opção pela República Oriental do Uruguai como destino da missão.

Essa reincidência de publicações e argumentações querendo "restabelecer a verdade adulterada dos factos” (A FEDERAÇÃO, 09/09/1913, p. 3) evidencia o anseio dos republicanos em, um segundo momento, de respaldar a decisão do governo. E mostra, ainda, o quanto os mesmos se utilizavam da palavra escrita como um instrumento pela consolidação do domínio republicano (CORSETTI, 2004) que neste caso, era legitimar a veracidade da ação governamental.

Sobre os argumentos apresentados, cabe salientar, que na maior parte das reportagens publicadas foi reiterado que a missão contribuiria para o avanço da realidade educacional do Rio Grande do Sul, a qual vinha aos poucos sendo transformada. E para comprovar esse contexto de mudanças e refutar as colocações apresentadas no Correio do Povo, foram utilizados nas reportagens apresentadas: dados comparativos entre os estados de São Paulo, Rio de Janeiro e Minas Gerais a fim de evidenciar que o Rio Grande do Sul não possuía uma instrução atrasada; dados dos Relatórios anuais da Secretaria de Estado dos Negócios do Interior e Exterior relativos à instrução pública e, ainda, referências do Uruguai mostrando o quanto aquele país vinha avançando em seu sistema educacional e, por isso, era digno de receber uma missão pedagógica. 
Outro aspecto que chama a atenção no que faz referência a essas reportagens é o espaço que elas ocupavam no jornal, tanto as do Correio do Povo, contrárias, como também as de $A$ Federação, defendendo a estratégia adotada pelo Estado. Diferentemente das notícias informativas, as notícias da categoria de caráter argumentativo eram notícias extensas, ocupando duas ou mais colunas. A maior parte estava localizada nas capas e/ou logo nas primeiras páginas de ambos os jornais. Possuíam títulos em negritos, com letras maiores e alusivos a discussão que estava em pauta, o que sem dúvida, chamava a atenção do leitor. Essas questões incidem na compreensão de que determinadas reportagens recebiam, em detrimento de outras, mais ênfase.

Com as mesmas características e, talvez, com a mesma intenção de representatividade, foram identificadas as reportagens com as impressões dos comissionados. Assim, do mesmo modo, elas foram, em maior parte, identificadas nas capas ou logo nas primeiras páginas das edições. Os títulos em letras maiores eram referentes àquilo que o leitor iria encontrar no conteúdo da notícia. Eles eram repetitivos, estando em torno de: "Professores rio-grandenses no Uruguay", "Missão Escolar", "As primeiras impressões dos professores rio-grandenses no Uruguay".

As primeiras notícias sobre os trabalhos que estavam sendo realizados pelos professores em Montevidéu, no ano de 1913, foram divulgadas pelo jornal Correio do Povo em 03 de outubro. Essa reportagem indicou que os comissionados foram recepcionados no porto da capital pelo Inspetor uruguaio Luiz Pecantel. No dia seguinte foram apresentados à Comissão Departamental da Instrução Pública e, posteriormente, ao Conselho da Instrução do Departamento. Indicou ainda, que logo nos primeiros dias o grupo se organizou em dois subgrupos para melhor desempenhar suas tarefas. O primeiro era composto por Alfredo Clemente Pinto, Marieta e Florinda e, o segundo, por Georgina, Affonso Guerreiro Lima e Ondina. A reportagem mostrou ainda que a comissão estava sendo esperada nas escolas pelas crianças com cartazes e frases de boas vindas, sendo que várias crianças os aguardavam na frente da escola com bandeirinhas do Brasil e do Uruguai. Indicou ainda, que a primeira visita tinha sido realizada na escola de $1^{\circ}$ grau no 9 e que o grupo de professores rio-grandenses foi bem recebido tanto pelos alunos como pelos profissionais da instituição.

Posterior a essa notícia no Correio do Povo, só identificamos informações no jornal $A$ Federação. $\mathrm{O}$ mesmo publicou sua primeira nota sobre as impressões da viagem no mês de novembro e em uma sequência de três notícias. As duas primeiras apresentaram uma síntese do Relatório encaminhado aos dirigentes do Estado pelo grupo que estava em Montevidéu em 1913, e a última anunciou que o grupo de professores já havia enviado o segundo relatório, o qual foi divulgado no jornal apenas nas edições de 1915. Todavia, como não estamos trabalhando com os dados divulgados no referido ano, cabe apenas o destaque.

Através das reportagens publicadas tanto no Correio do Povo como em $A$ Federação, sobre as impressões dos viajantes, foi possível apreender que o primeiro noticiou as primeiras atividades dos professores rio-grandenses no Uruguai enquanto o segundo procurou transcrever literalmente alguns trechos do Relatório Oficial que havia sido entregue pelo grupo de professores que viajou em 1913. Talvez objetivando apresentar os principais resultados desse primeiro momento da missão. 
Assim, a partir da leitura dessas reportagens, evidenciamos que os principais destaques feitos pelos professores foram: (i) a infraestrutura dos prédios uruguaios adequada às exigências da higiene e da Pedagogia; (ii) a presença de cartazes com preceitos de civilidade e moral em todas as instituições visitadas bem como uma disciplina e ordenamento de cunho cívico e patriótico; (iii) a superioridade do método João de Deus, utilizado no RGS, em relação ao utilizado nas classes uruguaias de leitura; (iv) a necessidade de ter pessoas preparadas pedagogicamente para assumir as aulas da Escola Complementar, assim como, a importância de destinar às escolas anexas a essa, o exclusivo preparo pedagógico dos futuros professores.

Quanto as impressões do grupo que esteve em Montevidéu estudando e praticando na Escola Nacional de Senhoritas e na de Aplicação no ano de 1914, não identificamos nas edições aqui analisadas nenhuma referência.

\section{Conclusão}

Nesse trabalho tivemos como objetivo identificar o que foi divulgado pelos periódicos sul-rio-grandenses acerca da missão encaminhada ao Uruguai nos anos de 1913 e 1914. Tratava-se de uma missão que tinha como intuito estudar a organização educacional uruguaia a fim de qualificar a educação gaúcha. Para tanto, pesquisamos as edições de 1913 e 1914 de dois jornais: A Federação e o Correio do Povo.

A partir da análise das reportagens identificamos que ambos os jornais divulgaram notícias sobre a missão. Ao todo, entre as edições de 1913 e 1914, foram encontradas 43 reportagens, das quais a maioria era referente à viagem de 1913. O que nos mostra que a mesma teve uma "cobertura" maior pelos periódicos. De forma geral, A Federação apresentou um número maior de publicações sobre a missão. Contudo, as análises evidenciaram que houve uma preponderância de reportagens d' $A$ Federação sobre a primeira viagem, realizada no de 1913, e um predomínio de notícias da segunda viagem, no ano de 1914, por parte do Correio do Povo.

Nesse sentido, a categorização das reportagens possibilitou aprofundar as análises e identificar que as "tendências políticas" dos dois jornais estiveram relacionados aos conteúdos e as formas com que as reportagens foram publicadas. A Federação, nesse caso, configurou-se como um legítimo defensor da estratégia adotada pelo seu partido divulgando, principalmente, notícias argumentativas e as que continham as impressões dos professores com as possíveis contribuições e/ou "resultados" da missão. Foi possível evidenciar ainda, que as reportagens argumentativas e com as observações dos comissionados ganharam ênfase sob as reportagens de caráter informativo, as quais foram reincidentemente encontradas com dimensões pequenas e em uma seção localizada quase ao final dos dois jornais.

Por fim, salientamos que havia um evidente interesse das autoridades governamentais de noticiar por meio dos periódicos locais, o andamento da missão educacional enviada ao país vizinho. Para além do interesse da possibilidade real de alavancar a educação sul-rio-grandense, o governo republicano buscava também vender a imagem de uma administração moderna, eficiente e preocupada com os rumos a serem tomados pelo Estado. 


\section{Referências}

ALVES, F. N. Imprensa. In: BOEIRA, N.; GOLIN, T. (Orgs.) Império. Coleção História Geral do Rio Grande do Sul. v. 2 Passo Fundo: Méritos, 2006. pp. 351-372.

BARRÁN, J. P. La espiritualización de la riqueza: catolicismo y economia en Uruguay, 1730- 1900. Montevideo: Ediciones de la Banda Oriental, 1998.

BRALICH, J. Breve Historia de la educación en el Uruguay. Montevideo: Ediciones del Nuevo Mundo, 1987.

CAETANO, G. Lo privado desde lo público. Ciudadanía, nación y vida privada em el Centenario. In: BARRÁN, J. P.; CAETANO, G.; PORZECANSKI, T. (Dirección). Histórias de la vida privada en el Uruguay. Tomo3. Individuo y soledades (19201990). Montevideo: Ediciones Santillana,1998.

CORSETTI, B. Controle e Ufanismo: A escola pública no Rio Grande do Sul (1889/1930). Tese de Doutorado. Programa de Pós-Graduação em Educação, Universidade Federal de Santa Maria. UFSM, RS, 1998.

O positivismo como base do pensamento educacional no Rio Grande do Sul (1889/1930). In: Anais Anped-sul, 2004. Disponível em: <http://www.portalanpedsul. com.br/admin/uploads/2004/Paine1/Painel/11_58_59_O_POSITIVISMO_COMO_BASE_ DO_PENSAMENTO_EDUCACIONAL_NO_RIO_GRA.pdf $>$. Acesso em 05 out. 2014 .

CHAMAON; C. S.; FILHO, L. M. F. A educação como problema, a América como destino: a experiência de Maria Guilhermina. In: MIGNOT, A. C. V.; GONDRA, J. G. (Orgs.). Viagens Pedagógicas. São Paulo: Cortez, 2007.p. 39-64.

DEMARCHI, M.; RODRIGUEZ, H. José Pedro Varela. Tradução José Rubens de Lima Jardilino. Coleção Educadores. Recife: Fundação Joaquim Nabuco, Editora: Massangana, 2010.

ESPIG, M. J. (Org.). Notícias de uma guerra do Centenária: O Movimento do Contestado através do jornal A Federação (1912-1916). São Leopoldo: Oikos, 2013.

FRANCO, S. C. Dicionário Político do Rio Grande do Sul (1821-1937). Porto Alegre: Suliani Letra \& Vida, 2010.

GIOLO, J. Estado, Igreja e Educação no RS da Primeira República. Tese de Doutorado. (Doutorado em História e Filosofia da Educação). Faculdade de Educação da Universidade de São Paulo. SP. 1997.

GREISSING, C. Conflictos y tensiones en el debate por la educación durante el Centenario (1910-1934). In: CAETANO, G. Los uruguayos del Centenario: nación, ciudadanía, religión y educación (1910-1930). Montevideo: Ediciones de la Banda Oriental, 2000.

LUCA, T. R. História dos, nos e por meio dos periódicos. In: PINSKY, C. B. (Org.). Fontes Históricas. São Paulo; Contexto, 2005. p. 111-153.

ORESTES, A. Historia de la Escuela Uruguaia. Montevideo, El siglo Ilustrado, 1911.

PERES, E. T. Aprendendo formas de pensar, sentir e de agir. A escola como oficina da vida: discursos pedagógicos e práticas escolares da Escola Pública Primária Gaúcha (1909-1959).

Tese de Doutorado. Programa de Pós-Graduação em Educação, Universidade Federal de Minas Gerais. UFMG, 2000.

PORTO ALEGRE. A Federação. Edições de 1913 e 1914. Disponível em: < http://memoria. bn.br/DocReader/docreader.aspx?bib=388653\&pasta $=a n o \% 20191 \&$ pesq= >. Acesso em: jan. 2014.

Correio do Povo. Edições de 1913. Núcleo de Pesquisa em História, UFRGS, RS. 
PORTO ALEGRE. Correio do Povo. Edições de 1914. Arquivo Histórico de Santa Maria, RS.

RIO GRANDE DO SUL. Relatório apresentado ao Sr. Dr. A. A. Borges de Medeiros. Presidente do Estado do Rio Grande do Sul. Pelo Dr. Protásio Antonio Alves. Secretário de Estado dos Negócios do Interior e Exterior, 1914. Disponível na Biblioteca Rio-Grandense. Rio Grande/RS.

SILVA, J. M. M. et al. Breve histórico da imprensa sul-rio-grandense. Porto alegre: Corag, 1986.

TAMBARA, E. Positivismo e Educação: a educação no Rio Grande do Sul sob o castilhismo. Pelotas: Editora Universitária/UFPel, 1995.

ZICMAN, R. B. História através da imprensa - algumas considerações metodológicas. Projeto História, São Paulo: n. 4, 1985.

\section{Nota}

${ }^{1}$ Instituição responsável pela formação de professores.

* Doutoranda em Educação pela Universidade Federal de Pelotas, Pelotas, Rio Grande do Sul, Brasil.

* Professor doutor da Universidade Federal de Pelotas, Pelotas, Rio Grande do Sul, Brasil.

\section{Correspondência}

Eduardo Arriada - Universidade Federal de Pelotas, Faculdade de Educação, Departamento de Fundamentos da Educação. Rua Coronel Alberto Rosa, n. 154, Centro, CEP: 96001-700, Pelotas, Rio Grande do Sul - Brasil.

E-mail: caroli_brga@yahoo.com.br - earriada@hotmail.com

Recebido em 13 de novembro de 2014

Aprovado em 11 de novembro de 2015 